\title{
ÁLVARO B. MÁRQUEZ-FERNÁNDEZ: EL OCASO DE LA CIUDADANÍA LIBERAL Y EL SOL NACIENTE DE NUEVAS CIUDADANÍAS EN LA ERA DE LA GLOBALIZACIÓN
}

\author{
Álvaro B. Márquez-Fernández: The decline of liberal citizenship and \\ the rising sun of new citizenships in the era of Globalization
}

Katia Martínez Heredia*

\section{RESUMEN}

El objetivo de este artículo es comprender el pensamiento de Álvaro B. MárquezFernández, desde los principios filosóficos y epistemológicos de la teoría antihegemónica latinoamericana, la conciencia crítica y la praxis emancipadora de los sujetos, quienes se develan, se revelan, se resisten y emergen ante el poder neoliberal enraizado en América Latina en la era de la globalización. Todo ello implica una reflexión sobre la crisis de la ciudadanía liberal instalada desde la Revolución Francesa, la importancia y relevancia de las nuevas ciudadanías, que adquieren la connotación y representación social de movimientos sociales emergentes con poder social, político e intercultural en nuevos escenarios de acción y participación. No es una concepción absolutista, positivista o metafísica del poder en su intención por controlar la condición de vida de los seres humanos. El carácter deliberativo y plebiscitario de este nuevo tipo de poder político y de democracia participativa, anuncia el esfuerzo por elaborar una teoría política de la participación ciudadana basada en unos principios de justicia y de equidad que se obtienen por discusión y acuerdo público de una democracia sub-alterna ciudadana.

Palabras clave: ciudadanía liberal, nuevas ciudadanías, globalización, América Latina.

RECIBIDO: Marzo 2019

ACEPTADO: Abril 2019

\footnotetext{
* Doctorado en Ciencias Sociales en Universidad del Zulia. Magistra en Estudios Políticos en Pontificia Universidad Javeriana de Bogotá. Licenciada Ciencias de la Educación con Especialidad en Lenguas Modernas Español-Inglés en Universidad del Atlántico. Comunicadora Social-Periodista con Énfasis en Comunicación Político-Económico en la Universidad Autónoma del Caribe. Docente e Investigador Universidad del Atlántico-Colombia. kathymilmh@gmail.com; katiamartinez@mail.uniatlantico.edu.co
} 
Álvaro B. Márquez-Fernández: el ocaso de la ciudadanía liberal y el sol naciente de nuevas ciudadanías en la era de la globalización

\begin{abstract}
The objective of this article is to understand the thinking of Álvaro B. MárquezFernández, from the philosophical and epistemological principles of the Latin American antihegemonic theory, the critical conscience and the emancipatory praxis of the subjects, who reveal themselves, reveal themselves, they resist and emerge before the neoliberal power rooted in Latin America in the era of globalization. All this implies a reflection on the crisis of liberal citizenship installed since the French Revolution, the importance and relevance of new citizenships, which acquire the connotation and social representation of emerging social movements with social, political and intercultural power in new action scenarios and participation. It is not an absolutist, positivist or metaphysical conception of power in its intention to control the condition of life of human beings. The deliberative and plebiscitary character of this new type of political power and participatory democracy, announces the effort to elaborate a political theory of citizen participation based on principles of justice and equity that are obtained through discussion and public agreement of a sub democracy -alterna citizen.
\end{abstract}

Key words: liberal citizenship, new citizenships, globalization, Latin America.

\title{
A manera de Introducción
}

Según Álvaro B. Márquez-Fernández la emergencia de la ciudadanía liberal en el contexto de la Revolución Francesa (1789), dio paso a

"clases y/o actores sociales contextualizados por un orden jurídico que les permitió una libre participación de elección y opinión en el espacio público, así como relaciones de poder que se constituyen a través de la voluntad popular del conjunto social, con el fin de ejercer una participación directa sobre las gestiones públicas del Estado" (Márquez-Fernández, 2018: 71).

Sin embargo, con el pasar del tiempo el discurso de libertad, igualdad y fraternidad construido por los ciudadanos liberales desde Europa para el mundo, a través de los Derechos del Hombre y del Ciudadano no se han consolidado poniendo en ruptura los poderes públicos del Estado moderno y los poderes societales de los ciudadanos, "colocando en crisis la representatividad de la ciudadanía frente a un Estado que se legitima a través de ella" (Márquez-Fernández, 2018: 71).

Ante tal crisis la producción social y cultural de los ciudadanos es multi e intercultural e implica la identificación y el reconocimiento de los valores, las costumbres, las tradiciones, las creencias, la historia, los modos de vida, las prácticas 


\section{Katia Martínez Heredia}

Telos Vol. 21, No. 2 (2019). 451-471

sociales y ciudadanas, las orientaciones éticas y morales, y todo el conjunto de relaciones sociales entre los sujetos que hacen posible la participación y la intercomunicación dialogante. Se empieza a desplazar la crítica política y se presta especial atención a la crítica cultural, sin abandonar la crítica al Estado y su responsabilidad social y constitucional sobre los ciudadanos, quienes exigen acceso a la cultura, a la diversidad, a la integración, a la igualdad y a la equidad, como derechos fundamentales y principios humanos vinculantes de toda sociedad libre y democrática.

Aquí, "las multitudes emergen como sujetos plurales y colectivos, pero principalmente como sujetos políticos, ya que son las multitudes quienes proponen una nueva lógica del discurso político, en torno a asuntos comunes de la esfera pública no estatal, que incorpora una dimensión privada no representativa" (Martínez Heredia, 2012: 53). Para Paolo Virno en su texto Gramática de la Multitud, las multitudes son consideradas como "tejidos de individuos" (2000: 76) que ejercen una acción colectiva, o gama de individuos interactuantes que reviven una nueva alternativa de subjetividad frente a lo que acaece y no se detiene, sobre ese conjunto de acontecimientos que vienen en cascada, y que estos seres pensantes critican y reconfiguran, hacia un nuevo orden de entendimiento y de aprehensión de la política.

Las nuevas ciudadanías como las denomina Álvaro Márquez-Fernández asumen una actitud ética sobre su papel en la historia, comprenden las alternativas posibles desde los conocimientos, saberes, valores y principios aprehendidos, en su condición de sujeto ético, quien hace un análisis histórico de las barreras que se le imponen y experimenta nuevas formas de subjetivación que le dan la posibilidad de transgredirlos, como "una nueva posibilidad de acción política, no desde el plano de la dominación sino desde la organización social” (Martínez Heredia, 2015: 24).

La visión alternativa de las nuevas ciudadanías sugiere la emancipación de multitud de ciudadanos del mundo de diversidad étnica, racial y sexual, de diferentes nacionalidades y condición socio-económica y socio-política, en espacios importantes 
Álvaro B. Márquez-Fernández: el ocaso de la ciudadanía liberal y el sol naciente de nuevas ciudadanías en la era de la globalización

de reconocimiento y visibilización a escala planetaria, lugares estratégicos que acaparan la atención de la comunidad internacional y medios alternativos de divulgación, igualmente globales de manera democrática para ser legitimados por la sociedad y la opinión pública mundial. "A ello se refiere el cuerpo social, no el de la sociedad civil cooptada históricamente por el Estado, sino el de las multitudes que emergen como una estrategia vigorosa de acción colectiva" (Martínez Heredia, 2015: 46), debido a la saturación de los grandes sistemas como el Estado moderno, de tal suerte que lo que surge es una desinstitucionalización de los poderes establecidos y la materialización de un poder multiforme y multicolor.

La emergencia de las nuevas ciudadanías se mantienen con rigor en el plano nacional como internacional teniendo visibilización en la era de la globalización con apuestas renovadoras y con objetivos que integran intereses de todo orden, sin distingo de clases y bajo ópticas matizadas que responden a un constructo cultural que se asoma con fuerza y determinación. Ya decía Weber que "la política consiste en una dura y prolongada penetración a través de tenaces resistencias, lo que requiere simultáneamente de pasión y mesura (...) que en este mundo no se consigue nunca lo posible si no se intenta lo imposible una y otra vez" (1979: 178), a través de la "lucha social" (Foucault, 1984: 91).

Es por ello que el objetivo de este artículo es poder comprender el pensamiento de Álvaro B. Márquez-Fernández, desde los principios filosóficos y epistemológicos de la teoría antihegemónica latinoamericana, la conciencia crítica y la praxis emancipadora de los sujetos, quienes se develan, se revelan, se resisten y emergen ante el poder neoliberal enraizado en América Latina en la era de la globalización. Todo ello implica una reflexión sobre la crisis de la ciudadanía liberal instalada desde la Revolución Francesa, la importancia y relevancia de las nuevas ciudadanías, que adquieren la connotación y representación social de movimientos sociales emergentes con poder social e intercultural en nuevos escenarios de acción y participación pública. 


\section{El ocaso de la ciudadanía liberal en la era de globalización neoliberal}

Para Álvaro B. Márquez-Fernández "subsanar estas crisis de la ciudadanía liberal en la sociedad moderna implica todo un proyecto de reconstrucción de la política que exige una compleja crítica teórica a los fundamentos positivistas del Estado" (2018: 72), ya que desde el punto de vista del liberalismo contemporáneo o el neoliberalismo de siglo XXI el crecimiento económico está por encima del desarrollo social de los pueblos, en un exigente camino por la expansión y la mundialización del libre comercio y el libre mercado inter-continental, el cual intensifica el autogobierno y la lógica de acumulación-monopolización-explotación, donde (1) la fuerza de trabajo o fuerza productiva adquiere la connotación de mercancía, (2) la acumulación no revierte sobre el trabajador y da lugar a la ganancia del empresario, y (3) la monopolización, como fin último, busca la posesión exclusiva de la fabricación o la comercialización de un producto o servicio en el orden nacional e inter-continental en un contexto de competencia desleal.

Es por ello que el poderío transnacional de la globalización no es neutro, tiene una intención e identidad: la racionalidad del mercado (Márquez-Fernández, 2006), que impone su lógica transaccional y mercantil, sus ideas, sus rituales y sus valores, afectando un innumerable de actividades culturales y societales, comercializando todo y bombardeando a la sociedad con conceptos como competitividad, crecimiento económico o mercado, asociados a la idea de progreso, desarrollo y crecimiento impuestos por el sistema económico capitalista occidental en vigor, donde el capital es esencial.

Es así como la era de la globalización neoliberal está generando una "cultura" de identidades adaptativas, en plena conciliación y equilibrio con el modelo societal de un Estado que ha abandonado su rol asistencialista, por el de gestor en los mercados de capitales internacionales (Márquez-Fernández, 2006), que transforman la cultura, a través de la unificación neoliberal, sinónimo de uniformización de conductas, deseos, 
Álvaro B. Márquez-Fernández: el ocaso de la ciudadanía liberal y el sol naciente de nuevas ciudadanías en la era de la globalización

valores, representaciones, creencias, tradiciones, etc., continuamente inducidas por los sistemas de intercambios y de consumo, principal ley de la competencia y de la supervivencia depredadora del capitalismo postindustrial (Márquez-Fernández, 2006), por medio de la ideología universalista y fundamentalista del Mercado, que obvia al otro en una sociedad virtual, lo homogeneiza y lo deshumaniza.

Sin embargo, para Álvaro Márquez-Fernández es inminente "una praxis emancipadora que pueda suprimir el poder de las ideologías por medio de una pragmática discursiva que haga suficientemente fáctica la inclusión del otro" (2018: 72), donde se generan nuevas formas de manifestación, es decir, nuevos procesos culturales que maximizan la producción social, creando espacios marginales de explosión social y cultural, donde la sociedad se une para expresarse e interactuar local o globalmente, siendo éste un poder instituyente en evolución, en la que el diá-logos sea el proceso de comprensión y de interpretación sobre medios y fines (...) que busca abrir las riquezas propias del mundo intersubjetivo, como un proceso que tiende a favorecer el acceso a la diversidad racional, la pluralidad ideológica, como alternativa (Márquez-Fernández, 2006).

Es lo que Foucault llama la semiótica de la revuelta, citando a Francis Bacon en el Ensayo sobre la Sedición, de la edición de 1979, consistente en "una inversión de valores o en todo caso de apreciaciones, cuando el receptor de una orden en vez de aceptarla, empieza a interpretarla, a insertar su propio discurso entre el mandato que recibe y la obediencia que normalmente debería seguirlo" (2004: 312), cosa que se reviste de importancia, ya que emergen sujetos de poder-saber, con pluralidad de objetivos y desarrollos discursivos que le dan sentido a su accionar en defensa de la vida como principio máximo. Para Álvaro Márquez-Fernández "las nuevas ciudadanías se hacen presentes por causa de las crisis sistémicas de los poderes constituidos de una formación estatal que resulta históricamente insuficiente para resolver la conflictividad social y mantener su hegemonía" (2018: 73), de tal suerte que "esta es un importante caracterización y distinción de las nuevas ciudadanías, debido a que el énfasis con el 


\section{Katia Martínez Heredia}

Telos Vol. 21, No. 2 (2019). 451-471

que se promueve su praxis colectiva está dotado de un ejercicio reflexivo y discursivo cada vez más profundo y concientizador" (2018: 74), con el objetivo de generar procesos de cambio y transformación en las sociedades, partiendo de la conciencia de los derechos humanos y las libertades públicas.

Según Álvaro B. Márquez-Fernández la crisis de la ciudadanía liberal, "es una crisis que nos habla de un Estado hegemónico cuyos procesos democráticos no logran emancipar a sus ciudadanos del poder opresor y represor del mismo" (2018: 80), no obstante, las nuevas ciudadanías aluden a su derecho legítimo de defensa, resistencia y autodeterminación contra la opresión, bajo la exigencia de alcanzar los derechos humanos y las libertades públicas, disponiendo y apelando a la "construcción de sus imaginarios más originales y simbólicos, a sus referentes de moralidad pública compartida, a la par y junto a otros que por similares intereses se hacen solidarios y coparticipes de estos nuevos discursos y legitimaciones que les permitan ejercer derechos de ciudadanía más plurales y democráticos” (2018: 80).

\section{El sol naciente de nuevas ciudadanías en la era de la Globalización}

Para Álvaro B. Márquez-Fernández (2016), las transformaciones históricas son consecuencias de las prácticas socio-económicas de los colectivos humanos y sus respectivas instituciones estatales. La representación social con la que se pueden interpretar las bases materiales de esas relaciones, en todo momento, va a depender de los roles políticos que asuman los sujetos para producir el consenso o la disidencia que hacen que prevalezcan o no, las tendencias del modelo productivo. Se deduce, por consiguiente, que el nexo entre la esfera económica de la vida social y el contexto histórico donde se desarrollan las disrupciones del sistema, no dejan de responder a las circunstancias y posiciones de sus contradicciones dialécticas. Las relaciones de producción están asociadas a los medios y fuerzas productivas que generan, en el tiempo, la prospección del statu quo del modo de producción que busca su hegemonía, 
Álvaro B. Márquez-Fernández: el ocaso de la ciudadanía liberal y el sol naciente de nuevas ciudadanías en la era de la globalización

a efecto de hacer coactivas las fuerzas divergentes que pudieran fracturar el universalismo de la economía que pretende un sistema unidireccional.

Los años 90`s fueron para el mundo un período determinante, decisorio y de transición hacia el mundo globalizado. La bipolaridad ideológica existente había provocado nuevas transformaciones, evidentes entre los países y en los ciudadanos del mundo entero. Nociones como inclusión y exclusión, dependencia e interdependencia, globalizados, des-globalizados, desarrollados y subdesarrollados, industrializados y pre-industriales, serían el nuevo lenguaje a utilizar dada la compleja connotación que surge a propósito de la globalización.

Según Márquez-Fernández (2016), en la Modernidad, se busca unificar los mercados del consumo por medio de la aplicación de estéticas públicas que garanticen la adhesión simbólica a los patrones de control inmersos en las representaciones sociales. La tesis principal que caracteriza a estos modelos económicos de la producción, a partir de la Modernidad, es crear y fortalecer por todos los medios, una economía de mercado que sea potencialmente inclusiva de todos aquellos sujetos dotados, por el sistema económico, de alguna capacidad para el consumo. Y así se convierten, sin mayor conciencia de los procesos subyacentes de la alienación ideológica, en "sujetos" con capacidad para reproducir las relaciones de intercambio y de consumo que suscita y promociona el mercado capitalista para, generalizar y globalizar los intereses individuales de un colectivo social que responde a "intereses comunes" a través de las analogías de sus roles de clases.

Expansión que puede analizarse de diversas maneras. Según Anthony Giddens, la globalización puede definirse como "la intensificación de las relaciones a escala planetaria" (1994: 70); Zygmunt Bauman afirma que "la globalización significa que todos dependemos los unos de los otros. Lo que sucede en un lugar puede tener consecuencias mundiales" (2007: 45); Así mismo, Fazio Vengoa argumenta que "con base en estas interrelaciones no solo se estimula el surgimiento de grandes sistemas, el nivel global, sino que se transforman igualmente los contextos locales y personales 


\section{Katia Martínez Heredia}

Telos Vol. 21, No. 2 (2019). 451-471

(cotidianos) de experiencia social" (2001: 14). Para Márquez-Fernández (2016), la tendencia hegemónica de la racionalidad capitalista es, inobjetablemente, radicalizar la sobreproducción y el consumo a través del control tecnológico del mercado que sirve de mediación para la reproducción del sistema capitalista. A su vez, esto da luz verde a las nuevas formas de acumulación de capital global al insertar en un sistema de redes telemáticas los nuevos roles de integración social, más allá de la temporalidad presencial de sus actores.

Este particular fenómeno de la expansión capitalista a nivel planetario, surge como una consecuencia, inevitablemente negativa, del pensamiento homogéneo e instrumental del desarrollo de las tecnologías y los inéditos escenarios que apuntan a controles sociales más alternativos y dialogados. Su efectividad subliminal es mucho más represora que en otras épocas. Pues, hoy día, los procesos de ideologización están mucho mejor revestidos por las simbolizaciones de un hedonismo pasivo que subyace en el imaginario político de la hegemonía del sistema. Los intereses y necesidades se permean mucho mejor a través de la estructura de consuno del mercado capitalista. De allí la ilusión democratizadora que hace el mercado cibernético al simular la apropiación de conocimientos por parte del usuario sobre las representaciones sociales de la realidad.

Son las nuevas técnicas de la gubernamentalidad neoliberal capitalista o "tecnología gubernamental, cuya medida racional debe ajustarse jurídicamente a una economía entendida como proceso de producción y de intercambio" (Foucault, 2007, p. 336), que busca expandirse, a través de los agentes económicos que dinamizan el comercio internacional, a través de "un nuevo arte de gobernar a la sociedad civil mundial u homo economicus, en un contexto donde el mercado mundial escapa al Estado, mientras éste lo vigila a través de una pasividad teórica" (p. 333), en una época de múltiples cambios, reorganización geopolítica y geoeconómica del Estado-Nación en todo el planeta; en definitiva, una revolución económica con pretensiones globales, 
Álvaro B. Márquez-Fernández: el ocaso de la ciudadanía liberal y el sol naciente de nuevas ciudadanías en la era de la globalización

donde el actor principal es el mercado inter-continental, el nacimiento de una nueva tecnología del poder a escala planetaria llamada neoliberalismo en una nueva era denominada globalización.

Para Márquez-Fernández (2016) la hegemonía capitalista no cesa en su rol de razón universal toda vez que sigue siendo relevante ese thelos hegeliano que comprende la Historia como "progreso", y genera, permanentemente, un dispositivo de microfísica de poderes que le permiten su relegitimación a través de aquellos espacios públicos que le permite a la ciudadanía adherir nuevos patrones de movilidad social, sin perjuicio del orden hegemónico impuesto. Pero también, este tipo de hegemonía se cumple en un rol de génesis e innovación para recrear lo creado, de-construir lo constituido, repensar lo material por lo virtual, decodificar la diversidad en la unidad.

Y nos convence de lo inagotable de su poéisis tecno-científica, en su intento para producir la otra episteme que le permita racionalizar su poder de dominio a través de estrategias y alianza de inclusión ideológica. La nueva hegemonía del capitalismo persigue el control mediático y comunicativo que le sirve de plataforma para universalizar su mundo de vida. Para lograr ese objetivo prevé como urgente acelerar el modelo de producción de su racionalidad histórica, $v, g r$ la racionalidad cibernética, para hacer de su omnipresencia la realidad doméstica de nuestras vidas, cada vez más deshumanizadas por la condición de estar-ausencia que rodea la experiencia humana en los tiempos de la realidad virtual. Este es el contexto de análisis e interpretación, acerca del fenómeno de la globalización entendida como el tiempo de expansión postcapitalista de la producción y la plusvalía. Se viene acentuando una forma completamente desproporcionada y perversa de lo que pudiera llegar a darse como una relación simétrica entre el tener y el ser, el bien y la justicia, la equidad y solidaridad, de los seres humanos.

Las biopolíticas macro-económicas del F.M.I. (Fondo Monetario Internacional) y el B.M. (Banco Mundial) basan su análisis en el flujo de capitales desde los países desarrollados avanzados hacia los países subdesarrollados y pobres de capital, 


\section{Katia Martínez Heredia}

Telos Vol. 21, No. 2 (2019). 451-471

garantizando que la apertura de los mercados reduciría inmediatamente la pobreza, pero no es así. "The presumption was that the promised benefits of growth would, somehow, trickle down to the poor - though by then there was ample evidence that "a rising tide need not lead to the rise of all boats". (Stiglitz, 2002: 5).

Con frecuencia la discusión sobre el tema de la pobreza permitió caer en cuenta en varias fallas del mercado en la época dorada de los flujos de capitales a mediados de los años noventa, que dan cuenta de la mala distribución de la riqueza de las naciones subdesarrolladas en la nueva era de la globalización, mientras muchos ciudadanos se empobrecían cada vez más unos pocos recibían los beneficios del crecimiento económico, mientras muchos ciudadanos exigían al Estado mejoras en la condiciones de vida en educación, salud y empleo, las empresas públicas eran vendidas por sumas indescriptibles de dinero en el mercado mundial, dejando en manos de los privados e inversores extranjeros la estabilidad y el bienestar de muchas poblaciones en América Latina, donde se insiste en continuar en la carrera sistemática de la privatización de los bienes públicos y la desregulación del Estado. Es indiscutible la necesidad que se tiene de recuperar para la democracia las condiciones de vida que le deben permitir al ciudadano el desarrollo y culminación de una existencia feliz y benéfica. De igual manera, insistir en que se requiere, cada vez más, una ampliación de los derechos políticos, sociales y económicos, que hagan más viables los procedimientos por medio de los cuales se obtienen medios y fines que garanticen su cumplimiento (MárquezFernández, 2018).

Según Stiglitz (2004), si el Consenso de Washington tuvo sus frutos, aún no se ha gozado de ellos o por lo menos los ciudadanos promedio de muchos países aún no lo han hecho, visualizándose la precarización de la condición del empleo y de los trabajadores formales en esta región del mundo, donde la flexibilización laboral o desregulación del mercado laboral desestimula el empleo decente por los tipos de contrato de trabajo inestables, por las horas de trabajo remuneradas y no remuneradas 
Álvaro B. Márquez-Fernández: el ocaso de la ciudadanía liberal y el sol naciente de nuevas ciudadanías en la era de la globalización

en un escenario de explotación de los trabajadores, quienes están supeditados a salarios mínimos.

Se presenta una agudización de las condiciones de vida basadas en la inseguridad social, en la inestabilidad económica que depende de las ineficacias del mercado laboral y de las externalidades como las decisiones de consumo, el costo de los alimentos, el clima, etc., que recae sobre los ocupados económicamente, subempleados, empleos informales o empleos vulnerables como los vendedores ambulantes, el trabajo doméstico, el trabajo autónomo, el tendero, el vendedor de chicles, el artista ambulante y todos aquellos que obtienen un beneficio económico o un empleo por cuenta propia, siendo todo ello una marcada violación de derechos fundamentales que conllevan nuevamente a la polarización de clases sociales muy ricas y poblaciones muy pobres y marginales con escasas oportunidades y de realización de sus necesidades básicas.

Aunque la economía de América Latina se vio fracturada por un largo período, según Stiglitz "existe una gran desilusión del Consenso de Washington, que se refleja en la elección de gobiernos de izquierda en Brasil, Venezuela, Bolivia, Ecuador, Uruguay, porque prometen educación y atención sanitaria a los pobres" (2006: 66), mientras tanto los ocho países que conforman el milagro del Sureste Asiático, denominado así por su rápido crecimiento: Japón más los cuatro dragones o tigres: Hong Kong, Singapur, Taiwán, Corea, y tres países de reciente industrialización: Malasia, Tailandia e Indonesia, mejoraron su economía y el bienestar de la mayoría de la sociedad.

En este proceso, "el Estado hizo énfasis en estimular la educación científica y tecnológica que facilitara la transferencia tecnológica y el desarrollo del capital humano" (Stiglitz, 1997: 330), basando su desarrollo industrial en las exportaciones, en las inversiones de capital extranjero, dando acceso a los mercados internacionales así como a la tecnología, en la creación de entidades e instituciones destinadas a promover el ahorro donde el Estado se encargó de que los beneficios del crecimiento económico no fueran para unos pocos, avanzando rápidamente hacia el desarrollo social. 


\section{Katia Martínez Heredia}

Telos Vol. 21, No. 2 (2019). 451-471

Según Márquez-Fernández (2016), seguimos supeditados a un modo de producir la materialidad de la que pende la vida de todos, pero debe ser revertido desde la crítica de un humanismo socio-político capaz de garantizar la paz y el bien en común. Vale decir, no ceder a la tentación de universalizar o abstraer en sí mismo el fenómeno de la globalización, sino verlo como una superestructura o totalidad de la cultura hegemónica del post-capitalismo que incide negativamente en las condiciones de vida de la civilización humana. En un planeta donde todas las esferas de la vida tienen derecho a la existencia autónoma. No se debe dejar al "libre arbitrio" de las nuevas tecnologías la evolución de la plusvalía del capital. La crítica contra hegemónica que se asume en este texto le da la bienvenida a una nueva Esperanza donde los sujetos de la política sean, en todo, sujetos éticos de la Política.

Kant (1784), decía que el progreso de la Humanidad depende de poner en tela de juicio las constituciones inamovibles y hacerlo públicamente, no hacerlo significa violar los derechos del hombre, ahora les corresponde a los hombres de este tiempo replantear, reformular y repensar los paradigmas, las doctrinas instituidas durante siglos, las nociones, los conceptos, las teorías y las prácticas en las cuales están cimentadas las ciencias, y así poder transformar a la humanidad hacia la emancipación de su propia existencia, tal como lo menciona Álvaro B. Márquez-Fernández "es un cambio de paradigma donde la política no evade responsabilidades éticas y morales, pues se trata de recuperar para la praxis políticas la genuina praxis humanista del poder, ya que concede los beneficios de justicia social emancipadora" (2018: 81).

Ello representa resignificar, resemantizar y recategorizar a la política develando las "contraconductas de la gubernamentalidad" (Foucault, 2004: 407), en otras palabras los contrasentidos y las rupturas históricas que permiten hacer conexiones de una época a otra para comprender e interpretar el legado social y cultural de los sujetos emergentes presentes a lo largo de la historia. Es por ello que la Cultura se convierte en el ámbito de la vida en sociedad más importante puesto que permite crear y re-crear tejidos de 
Álvaro B. Márquez-Fernández: el ocaso de la ciudadanía liberal y el sol naciente de nuevas ciudadanías en la era de la globalización

significación entre los sujetos y prácticas simbólicas tangibles e intangibles en escenarios de diversidad y pluralidad en interacción social, económica y política, donde los sujetos se expresan como creación artística, referente, conducta, identidad, educación, patrón, práctica, modelo de vida, representación social, símbolo, valor y escenario de comprensión e interpretación, así como elemento de poder y saber.

Álvaro B. Márquez-Fernández y Doris Gutiérrez Fernández abogan por un filosofía intercultural, una reflexión sobre las culturas, donde "el diálogo intercultural es primariamente filosófico, pero en el sentido de las vivencias de los pensares y los saberes que en cada cultura se originan y se desarrollan" (2004: 15), defendiendo la condición humana como el lugar de la historicidad, desde el derecho de aparición del otro y el rescate de la pluralidad discursiva, donde las relaciones sociales intersubjetivas sean públicas y la comprensión del mundo de lo plural sean visibles. Desde el punto de vista de las nuevas ciudadanías se desarrollan luchas transversales que cuestionan el estatus del sujeto, es decir, la posición que asume el sujeto quien defiende su soberanía, su independencia y libertad, ya sea por la situación económica, política y social o cultural vigente, para trastocar y transformar lo que Álvaro B. Márquez-Fernández denomina el mercado de la ciencia que pretende cooptar la democracia, al estado y a la sociedad, donde la industria no tiene fibra moral que valore lo público sobre lo privado.

Las nuevas ciudadanías se hacen visibles contra todo abuso del poder siendo un fenómeno histórico que tiene su génesis en el momento en que el sujeto mismo se pregunta por su status o condición individual o colectiva, y tiene antecedentes en cada una de las etapas de la historia de la humanidad, donde han habido procesos sucesivos de avallasamiento más o menos profundos, vislumbrando la fuerte capacidad de lucha que han asumido los individuos a través del tiempo para contrarrestarlas, con la finalidad de defensa y reacción en un momento determinado frente a otros sujetos que también asumen posiciones y relaciones de poder-saber.

La visión alternativa de las nuevas ciudadanías sugiere " la emancipación con subjetividad y sin ciudadanía, cuya lucha no es política sino ante todo personal, social 


\section{Katia Martínez Heredia}

Telos Vol. 21, No. 2 (2019). 451-471

y cultural" (De Soussa, 2001: 180), de sentidos y contrasentidos que emergen, como alternativas de vida, quienes retornan a las teorías y prácticas heredadas de la tradición clásica que fundamentan la democracia y el estado social, en defensa de las libertades humanas, la dignidad humana, los derechos fundamentales, los principios de igualdad, equidad, justicia y respeto por la vida como valor máximo de la especie humana en general y del ser humano en particular, y reavivan los saberes y discursos instituyentes de la cultura originaria, traductores de la identidad cultural como signo y representación del pasado, del presente y del porvenir, en contraposición con la globalización de naturaleza depredadora y desreguladora del Estado.

Sin embargo, para Márquez-Fernández "Se da origen a una relación de contrapoder en sectores contenidos o represados por el poder del estado hegemónico, que fisura la organicidad lineal del poder impuesto por medio de otras praxis socio-políticas de participación ciudadana" (2018: 86), constituyéndose como Sujeto Histórico (Foucault, 1987), Multitudes (Martínez, Heredia, 2015), Nuevos Sujetos Sociales o Resistencias Anti-Sistema (Alonso, 2015), Sujetos Colectivos en tiempos extraordinarios (Gómez, 2014), Sujeto Insumiso (Salazar, 2008), Comunidades o Unidades heterogéneas Complejas (Najmanovich, 2005), Nuevos Movimientos Sociales-NMSs (De Soussa, 2001) o Sujetos Inter-Culturales (García Canclini, 2004).

Es por ello que en ese doble sentido de la hegemonía, coacción y consenso, es que las luchas de los movimientos sociales entran a jugar un rol protagónico en el desarrollo de la política en el espacio público a favor de los poderes democráticos del ciudadano. O dicho, en otros términos, el desarrollo de los poderes populares de la ciudadanía o sociedad, vistos como agentes de auto transformación de la política, es una distinción específica que marca las diferentes formas de praxis socio-políticas de los actores y/o ciudadanos en la recomposición orgánica de la democracia representativa (Márquez-Fernández, 2018). 
Álvaro B. Márquez-Fernández: el ocaso de la ciudadanía liberal y el sol naciente de nuevas ciudadanías en la era de la globalización

Es la revolución epistemológica de los sujetos, objetos y métodos que constituyen el sistema social, es "el poder insurgente del pueblo: actor genérico de la democracia ciudadana sub-alterna" (Márquez-Fernández, 2018: 94), debido a la emergencia del nuevo poder-saber de los movimientos sociales latinoamericanos emergentes en su praxis de cambio, ya que "tenemos que librarnos de ese conservadurismo cultural, al igual que debemos desasirnos de ese conservadurismo político" (Foucault, 1969: 39), es innegable que la sociedad y la cultura conviven en medio de sociedades políticamente democráticas pero socialmente fascistas, por tanto es imperativo dice De Soussa "crear un nuevo sentido común (...) una revuelta epistemológica desde el sur y es necesario que el sur se constituya como sujeto epistemológico porque hasta ahora ha sido un proyecto de esa naturaleza" (2015: 29), que proceda a una "ampliación simbólica de los saberes, prácticas y agentes sobre los cuales es posible actuar para maximizar la probabilidad de la esperanza" (De Soussa, 2010: 26) que trata de recuperar la dignidad de los grupos sociales dominados a través del tiempo en un territorio que era ajeno en la colonia y que a partir de prácticas de libertad se convierte en propio, entendiendo que "el sur es nuestra casa" (De Soussa, 2011: 44).

Para Márquez-Fernández (2018), se incrementan las dinámicas contrarias que entran en circulación para producir reacciones más puntuales e inmediatas para absorber en la marcha de los acontecimientos los liderazgos populares, pues es el único modo de salvar los inevitables enfrentamientos entre la ciudadanía y el poder del Estado. A la luz de este supuesto, la ciudadanía debe permanentemente construir estrategias que en un tiempo perentorio le permitan encausar las crisis del sistema hacia sus praxis emancipatorias. Se puede decir que la movilidad social y política de los actores debe cumplirse dentro del juego político de las crisis, y no convertirse en observadores externos.

La capacidad de gestionar las crisis dependerá, entonces, de esta inserción estratégica de la ciudadanía para la construcción de una conciencia política en total 


\section{Katia Martínez Heredia}

Telos Vol. 21, No. 2 (2019). 451-471

correspondencia con la complejidad de las crisis y de decisiones oportunas y efectivas. Le tocará a la ciudadanía, a través de la sociedad civil, recrear la dirección política del Estado a favor de una participación donde el poder ciudadano reside en la autonomía para elegir que el pueblo ostenta.

La revolución de las nuevas ciudadanías también es ideológica y política ya que impulsan el cambio social y cultural en sus comunidades y en sus territorios, se convierten en defensoras de la nación, por tanto asumen un papel protagónico representativo no electoral de la masa del pueblo, defensoras de los derechos humanos y las libertades humanas, defensoras de la pacha mama o madre tierra en el contexto de la globalización neoliberal capitalista extractora de los recursos naturales, siendo las artificies de los cambios estructurales, de las transformaciones y las rupturas generadas en las últimas dos décadas, alcanzados al interior de los Estado Latinoamericanos en defensa del derecho de autodeterminación y la soberanía del pueblo, en el contexto del estado social de derecho y la democracia, desarrollando y apalancando con mayor rapidez iniciativas populares de forma institucional, gubernamental y jurídico-legal.

Tal como lo plantea Márquez-Fernández (2018), el poder popular es un poder de insurgencia e insumisión para actuar en política. Un poder sin prescripciones o regulaciones a priori desconectadas de las experiencias de vida de la ciudadanía, un poder con lógicas alternativas capaz de incorporar en el universo de sus praxis sociopolíticas, otros espacios de interacción que favorezca la madurez política de las experiencias ciudadanas.

\section{Conclusión}

Para el maestro Álvaro B. Márquez-Fernández (2018) hablar del sol naciente de las nuevas ciudadanías y la crisis de las ciudadanías liberales en el contexto de la globalización es "hablar de una concepción intercultural y dialógica del poder, que es consecuencia de una manifestación plural y diversa de la praxis de los ciudadanos" 
Álvaro B. Márquez-Fernández: el ocaso de la ciudadanía liberal y el sol naciente de nuevas ciudadanías en la era de la globalización

(2018: 96), que requiere de la capacidad para reconocer la alteridad, comprender la diferencia y la divergencia en tanto condición intrínseca de los sujetos o sujetos libres con capacidad de relacionamiento, dialogar entre las culturas e interpretar el quehacer crítico y el saber espontáneo de los que hablan en la vida cotidiana en medio de los condicionamientos homogeneizantes y universalizantes del sistema de producción neoliberal de la cultura global.

La interculturalidad de las nuevas ciudadanías emergentes no suponen la aceptación o adopción de una cultura en otra como hibridación funcional o instrumental, de las culturas primitivas o indígenas en la cultura moderna globalizada, es la puesta en marcha de un conjunto de apuestas teóricas y prácticas, objetivas y subjetivas, éticas y estéticas que encuentran asilo en la co-construcción de los derechos, asumiendo la tarea de interrogar al pasado, interpelar el presente e interpretar "juntos" el futuro, mediante el poder Interpretativo que alude a rupturas emancipadoras de los sujetos en su praxis de cambio y en movimiento, ya que "los contenidos del diálogo intercultural se desarrollan principalmente más por el eje de la con-vivencia de las culturas, que por los procesos cognoscitivos que tiene cada cultural para organizar racionalmente el mundo y su entorno" (Márquez, 2004:15).

Estas nuevas esferas públicas se consideran esferas de cambio, en transformación y en ruptura, ya que se consideran esferas de auto-realización, autodeterminación y emancipación en las que emerge el devenir ininterrumpido de la sociedad, que se enriquece y se retroalimenta con las creaciones colectivas que se afianzan en la alteridad del diálogo, "porque considera la condición humana como el lugar de la historicidad, donde se generan los procesos verídicos de la con-vivencia y donde se debe contrastar la verdad con los discursos que la enuncian” (Márquez, 2004).

Para Márquez-Fernández (2018) no es una concepción absolutista, positivista o metafísica del poder en su intención por controlar la condición de vida de los seres humanos. El carácter deliberativo y plebiscitario de este nuevo tipo de poder político y de democracia participativa, nos anuncia el esfuerzo por elaborar una teoría política de 


\section{Katia Martínez Heredia}

Telos Vol. 21, No. 2 (2019). 451-471

la participación ciudadana basada en unos principios de justicia y de equidad que se obtienen por discusión y acuerdo público de una democracia sub-alterna ciudadana, donde frente al Estado Hegemónico, emergen nuevas ciudadanías o movimientos sociales en el espacio público, buscando la defensa del reconocimiento a la diversidad cultural y las diferentes identidades sociales de los derechos humanos y promoviendo la práctica del buen vivir, bajo la lógica esperanzadora de una praxis nueva, es decir, nuevas racionalidades para la racionalidad política.

En conclusión la co-construcción del sentido genuino de una democracia subalterna ciudadana desde la perspectiva de las nuevas ciudadanías representa una concepción alternativa de la dignidad humana ni superior ni inferior, se considera una revolución multidimensional de los sujetos emergentes en el espacio de la autodeterminación y la soberanía individual y colectiva para la co-construcción de un mundo en común, representa la interpelación a los supuestos teórico y prácticos fuera de toda ordenación que permite la ruptura a las disposiciones fundamentales de la cultura occidental, representa la desclasificación y desjerarquización del sistema de nombres, representa el devenir del discurso revelador del nuevo pensamiento y la alteración de las positividades, ya que es allí mismo en el campo de las representaciones donde es posible redescubrir el sentido y el universo de significaciones desde el cuerpo de la nación.

Por lo que resulta de indiscutible importancia, analizar los diversos planos de composición que sirven de sustento al Estado hegemónico y las mediaciones que se generan entre éste y la ciudadanía; sobre todo, cuando la hegemonía tiende a falsear la auténtica práctica popular de la democracia que debe hacer énfasis en el reconocimiento y aplicación de los derechos humanos de los ciudadanos y conceda los beneficios de justicia social emancipadora.

\section{Referencias Bibliográficas}


Álvaro B. Márquez-Fernández: el ocaso de la ciudadanía liberal y el sol naciente de nuevas ciudadanías en la era de la globalización

Alonso, Jorge. (2015). Prólogo. En: Pensar desde la resistencia anticapitalista y la autonomía. Centro de Investigaciones y Estudios Superiores en Antropología Social. Cátedra Jorge Alonso. México.

Bauman, Zygmunt. (2007). El desafío ético de la Globalización. En: Pánico en la Globalización. Fundación para la investigación y la cultura. Editorial FICA. Gobernación del Valle. Colombia.

De Sousa Santos, Boaventura. (2001). Los nuevos movimientos sociales. En: OSAL. Revista del Observatorio Social de América Latina. Argentina, No. 5, septiembre 2001. (Pp. 177-184).

De Sousa Santos, Boaventura. (2010). Descolonizar el saber. Ediciones Trilce. Uruguay.

De Sousa Santos, Boaventura. (2015). Construyendo la contrahegemonía:

traducción intercultural entre los movimientos sociales. En: Pensar desde

la resistencia anticapitalista y la autonomía. Centro de Investigaciones y

Estudios Superiores en Antropología Social. Cátedra Jorge Alonso. México.

Fazio Vengoa, Hugo. (2001). Globalización como proceso de larga duración. Reflexión

Política. Año $3 \mathrm{~N}^{\circ} 5$ Junio de 2001. Colombia. (Pp. 1-20).

Foucault, Michel. (1969). La arqueología del saber. Siglo XXI de Colombia Ltda. Colombia.

Foucault, Michel. (1984). El sujeto y el poder. Extraído de http://148.202.18.157/sitios/catedrasnacionales/material/2010a/martin_mora/ 3.pdf en fecha 26/01/2017.

Foucault, Michel. (1987). Hermenéutica del sujeto. Ediciones de la Piqueta. España.

Foucault, Michel. (2004). Seguridad, Territorio y Población. Fondo de Cultura Económica. Francia.

Foucault, Michel. (2007). El nacimiento de la biopolítica. Curso del Collége de France 1978-1979. Fondo de Cultura Económica. Primera Edición en español. Argentina.

García Canclini, Néstor. (2004). Desiguales, Diferentes y Desconectados. Mapas de Interculturalidad. Editorial Gedisa, S.A. España

Giddens, Anthony. (1994). Les consequénces de la modernité. Volumen 45. Número

5. Trad. de i'anglaisparOliever Meyer.L'Harmattan. Francia.

Gómez, Marcelo. (2014). El regreso de las clases. Clase, acción colectiva y movimientos sociales. Editorial Biblos. Argentina.

Kant, Emmanuel. (1784). ¿Qué es la Ilustración? En: Filosofía de la Historia. FCE. México.

Márquez Fernández, Álvaro y Gutiérrez Fernández, Doris. (2004). Raúl FornetBetancourt: diálogo y filosofía intercultural. Frónesis. Vol. 11, nº 3. Venezuela. (Pp. 9-39).

Márquez Fernández, Álvaro. (2006). Globalización neoliberal y crítica de la Filosofía intercultural. En: Salazar, Robinson (Ed). Salazar Robinson \& Chávez R, 
Alehandra (Comp.,). (2008). La Globalización indolente en América Latina.

Colec. Insumisos Latinoamericanos, Elalep.com, Argentina.

Márquez Fernández, Álvaro. (2018). En: Núñez Medina, Ignacio (coordinador). Democracia sub-alterna y estado hegemónico. Crítica política desde américa latina/ diálogo abierto con Álvaro B. Márquez-Fernández. El pregonero. Argentina.

Márquez Fernández, Álvaro. (2016). En: Martínez Heredia, Katia Milena. Políticas de la globalización. Organizaciones, Economía, Medio Ambiente, Cultura Y Universidad. Editorial Publicia. Co-autoría. Editorial Publicia. España.

Martínez Heredia, Katia Milena. (2012). Las multitudes, nuevos sujetos de creatividad y pluralidad en el contexto Bio-político contemporáneo. Encuentros, vol. 10, núm. 1, enero-junio, 2012. Colombia. (Pp. 51-68).

Martínez Heredia, Katia Milena. (2015). Política de las Multitudes. Medios alternativos de comunicación en el contexto biopolítico contemporáneo. Editorial académica española. Alemania.

Salazar, Robinson. (2008). Quien es el sujeto insumiso. Ruta de un nuevo sujeto. Universidad Autónoma de Sinaloa. México.

Stiglitz, Joseph E. y Wolfson, Leandro (1997) Algunas enseñanzas del milagro del Este Asiático en Desarrollo Económico, 37 (147), Argentina. (Pp. 323-349).

Stiglitz, Joseph. (2002). Whither reform? Towards a new agenda for Latin America. The Prebicsh Lecture. ECLAC, Chile.

Stiglitz, Joseph. (2004). Del Consenso de Washington a una Gobernanza Global. Banco Interamericano de Desarrollo. USA.

Stiglitz, Joseph. (2006). Cómo hacer que la Globalización funcione. Editorial Taurus. Colombia.

Weber, Max. (1979). El político y el Científico. El libro de Bolsillo. Alianza Editorial Madrid. Quinta edición. Sección Humanidades. España.

Virno, Paolo (2000). Gramática de la Multitud. Para un análisis de las formas de vida contemporánea. Puñaladas, ensayos de punta, Colihue. Argentina. 